\title{
The Application of Computer Technology in Graphic and Image Processing
}

\author{
Zhao Xiaolei \\ Weinan Normal University, Weinan, Shaanxi, 714000
}

Keywords: Computer Technology, Graphic Image, Composition, Application Field

\begin{abstract}
With the continuous progress of science and technology and the rapid development of social economy, computer technology has also got a qualitative leap. Graphics and graphics processing technology has also been widely developed in computer technology. With the development of living standard, the application of graphics and image technology is becoming more and more extensive, playing an important role in many fields. A simple description of the definition of computer graphics technology, then discussed according to the classification of computer graphics software, composition and application of computer graphics technology is expounded, so as to promote the development of the computer graphics technology.
\end{abstract}

\section{Introduction}

With the update and development of computer technology, computer graphics and image processing technology has made great progress, for example, from simple image design, modification and other aspects, it has developed into a strong professional discipline [2]. As we all know, the development of computer graphics and image processing technology is based on computer technology, and the development of computer technology affects people's living standard. The depth of industrial development has promoted the development of computer graphics and image processing technology, and computer has higher advantages in image processing and manual processing, which not only can effectively finish graphics and image processing, but also improve the work efficiency to a certain extent [2-3].

\section{An Overview of Computer Graphics and Image Technology}

Computer graphics and image processing technology, in brief, is a complete process of modifying, optimizing, finalizing the concept or descriptive image in computer, and displaying storage. The main function of computer graphics and image technology is to transform images by means of translation, rotation and scaling. Besides, in computer, images are stored digitally [4]. Therefore, restoration and segmentation of image encoding operation are compared; in addition, the computer graphics book can image modeling and modeling design, and design the corresponding color, shading and texture mapping and processing operations, enhance the image characteristics.

With the rapid development of information technology, innovation of computer technology, computer graphics technology is more perfect, and is widely used in various fields of society, and has its own characteristics, mainly includes the following four aspects: first, with efficient reproduction function. In traditional image processing technology, image quality is seriously affected by operation. For example, copy and storage will seriously affect it. In the existing computer graphics and image technology, image quality will not be affected by operation problems. Secondly, computer graphics and image processing technology needs higher bandwidth, which brings new requirements to the hardware devices of the computer [5]. If the basic equipment of the computer is not enough, it will increase the difficulty of computer graphics and image processing. Third, the use of a wide range of computer graphics and image sources, such as microscopes, astronomical mirrors, etc. can be used to deal with the technology. Fourth, the flexibility is strong. It can be processed in computer graphics and image technology in many areas of daily life or work, such as logical change, mathematical formula and so on. 


\section{Classification of Computer Graphics and Image Software}

Computer graphics and image technology also needs to be operated with software, and the level of software determines the production level of the production personnel to a certain extent. Generally speaking, image and image can be divided into six categories: engineering drawing production, rendering, film and television synthesis, 3D design, image processing, graphic design, typesetting software and so on [6]. Engineering drawing software commonly is used with Auto CAD. Lights cape is used in rendering the above, for the movie, commonly used with Adobe Premiere, Adobe After Effects Soft image/ XS, 3dsma; X, Maya are commonly used in our 3D design software; graphic image processing software Adobe Photoshop and CorelDraw graphic design software Freehand; Adobe PageMaker is used to do the typesetting processing.

\section{Computer Graphics Image Processing Technology}

The computer graphics image processing technology is mainly composed of three aspects, one is to enhance and restore the graphic image. In real life, a graphic image of the shooting is not entirely appropriate, some image quality is not high, you need to be enhanced, the key technology is that the use of noise, low-pass filter to remove the noise in the image, then use high pass filter to enhance the edges of high frequency signal. In this way, the sharpness and image quality of the graphic image can be improved. Computer graphics and image restoration technology refers to the problem of blurring and noise in images [7]. Computer graphics and image restoration technology can estimate original images based on known models and restore them. The graphic image is stored digitally on the computer, so that they need more memory, is not conducive to the transmission and storage of graphics, computer graphics and image compression technology in guarantee graphics without distortion, the compression at certain degree, reduce the storage space and transmission time. With the continuous development of compression technology, graphic image compression is divided into static image compression and dynamic image compression. Third, the computer graphics image processing technology can identify and describe the image, which is also one of the key technologies [8]. As we all know, the main purpose of graphics and image processing technology is to identify and match images, so that we can ensure the actual value of files, rather than the files that are immediately distributed.

\section{Comparison of the Operating Environment and Function of the Graphics Image Processing Technology in the Computer}

According to the configuration of computer can be divided into workstations and microcomputers; on the microcomputer software, there are various versions of Photoshop, 3DMAX, Auto, CAD and so on, these are the 3D animation and software design of PC system based on production, is widely used in the field of advertising, film, design etc.. Secondly, the software on workstations, such as Alias, TDI and so on, is mainly responsible for making graphics and images on workstations. The two have a clear division of labor, each has its own length, and it can also cooperate with each other. In terms of the two functions, the microcomputer is not superior to the workstation. Many aspects of the workstation are higher than the functions of the microcomputer, such as graphic display, memory capacity and CPU processing speed and the image quality generated by the workstation is higher than that generated by the microcomputer. From the aspect of modeling, 3dMax doesn't have the function of surface modeling [9]. If we need some complex surfaces, 3dMax is not easy to accomplish, nor can it achieve the desired results. But TDI can be successfully completed. From the interface, 3dMax is also difficult to make material business, and cannot see the material adjustment of the model. Only after the final image is generated, can we see the real effect. In TDI, however, the overall material and light source material can be seen, and the final results can be seen directly. So TDI's simulation of natural objects is better than 3dMax. The image generated by TDI is more natural and lifelike. 


\section{The Application of Computer Graphics and Image Processing Technology}

\subsection{Computer graphics and image processing technology can assist industrial design and manufacture}

Computer graphics and image processing technology is also widely used in the industrial field, the common one is CAD and CAu software. They are widely applied to product design and manufacture in industrial production, and are applied in the field of electronics, such as electronic circuits, integrated circuits, network analysis and so on. The technology of computer graphics and image processing can assist industrial design and industrial manufacture, and has the advantage of higher accuracy and efficiency. Compared with traditional manual design, it saves manpower and material resources. In addition, industrial design and manufacturing, high precision, but in a large-scale project that complex, artificial design can not meet the requirements of the circuit plate precision, using the technology of computer graphics and image processing, drawing and design can have high accuracy, effectively avoid artificial errors, so as to improve the quality of industrial design and manufacturing [10]. In the current situation, the production of industrial products is batch. The application of computer graphics and image processing technology in industrial manufacturing software can improve the quality of batch products. With the rapid development of social economy, industry is constantly improving and technology is constantly upgrading. This is closely related to the relationship between industrial design and manufacture and computer graphics and image technology.

\subsection{Scientific calculation of visualization}

The dependence of all walks of life on computer technology is enhanced, and the amount of information storage in the database has increased exponentially, which has virtually increased the technical difficulty of data analysis and processing. In the actual data operation process, data managers can not accurately retrieve huge data, nor can accurately induce the commonality of data, so that classification operation can not be completed. However, computer information technology can combine computer graphics and image processing technology, so that mass data classification operation can be realized and retrieval based on the basic characteristics of data can improve data processing efficiency and value [11]. This is the visual operation of scientific computing, which is widely used in the fields of medicine, meteorology, mechanics and so on. In the medical field, for example, remote surgery of the brain is realized by remote visual scientific calculation of high precision.

\subsection{The application of computer graphics and image processing technology in architecture and garden design}

Computer graphics and image technology is widely applied in the construction industry. The designer can express the space design of the architectural design quickly and clearly with the help of computers, so as to realize the rational design of the architectural design space. Designers can also use color rendering technology of computer graphics, visual display of the final results. Secondly, in the landscape design, the computer graphics and image processing technology is mainly used in the virtual reality of landscape design, and the 3D software is applied to deal with the landscape, so as to achieve the dynamic browsing effect [12].

\subsection{The application of computer graphics and image processing technology in animation and art}

With the upgrading of computer hardware, computer graphics and image technology is constantly improved, and the use of computer graphics is also more in-depth. High quality static graphic images are not enough to meet the needs of the advanced society, which makes computer animation produce. Art designers also make use of computer graphics and image processing technology to create art, which not only promotes the development of art design, but also promotes the development of art design software. The two complement each other. 


\subsection{The application of computer graphics and image processing technology in remote sensing image processing system}

Remote sensing technology is widely applied in agriculture, forestry, animal husbandry and fishery industry. Different bands of remote sensing technology can promote the rapid development of agriculture and other industries. The application of computer graphics and image technology to remote sensing technology can achieve automatic extraction of information. It is worth noting that the core of the remote sensing image processing system is the graphic image processing technology.

\section{The Future Development Trend of Computer Graphics and Image Technology}

With the rapid development of social economy and the continuous updating of computer hardware equipment, graphics and image technology has also attracted wide attention from all walks of life. As far as the current situation is concerned, there are the following aspects in the development of computer graphics and image processing technology.

First, computer graphics and image processing technology will be more clear and intelligent. The future graphic and image technology is highly automated, and also has the function of three-dimensional imaging. Second, the operation of computer graphics and image processing technology will be quicker and more convenient. Besides, the processing function of graphic and image will be more concentrated and simplify the basic operation steps. Third, the computer graphics image processing technology will have an updated algorithm and advanced knowledge of the idea. In the course of actual development, theory is a necessary condition and also the basis of practice. Advanced theoretical guidance is the theoretical basis for the development of computer graphics and image processing technology, and also an important means to enhance the actual operation of computer graphics and image processing technology. Therefore, if computer graphics and image processing technology wants to achieve sustainable development and update operation methods in time, we must learn from advanced theories and innovate continuously, so as to meet the needs of all sectors of society for computer technology.

\section{Conclusions}

In recent years, with the continuous improvement and improvement of computer technology, computer and network information has penetrated into every field of society, and people's dependence on computer technology has been continuously enhanced. With the development of social economy, computer graphics and image processing technology has been widely applied in many fields, such as industry, medicine, art, architecture and gardens. It further promotes the development of computer graphics and image technology. Therefore, the future computer graphics and image technology will be more clear, intelligent, and more simple to operate, and can meet the high needs of people.

\section{Acknowledgements}

This paper is grateful to the support of the fund project: the scientific research project of the Shaanxi Provincial Education Department (16JK1272).

\section{References}

[1] Wang Z Y. Graphic Image Processing Technology in the Application of the Film and Television Creation [J]. Advanced Materials Research, 2014, 1044-1045:1169-1172.

[2] Yang X G. Applications of Computer Graphics and Image Processing in Art Design[J]. Advanced Materials Research, 2014, 926-930:1688-1691.

[3] Fagundes L G, Santos R. Development of Computer Graphics and Digital Image Processing Applications on the iPhone[C]// Graphics, Patterns and Images Tutorials. IEEE, 2011:34-45. 
[4] Zhang S J. The Use of Computer Image Processing Technology in the Area of Graphic Design [J]. Applied Mechanics \& Materials, 2014, 687-691:3551-3554.

[5] Chen C Y, Wang F C, Chen X, et al. Application of Image Processing to Computer Graphics[J]. Advanced Materials Research, 2013, 765-767(2):2835-2838.

[6] Savransky D, Thomas S J, Poyneer L A, et al. Computer vision applications for coronagraphic optical alignment and image processing. [J]. Appl Opt, 2013, 52(14):3394-3403.

[7] Zou S X. Research on the Application of Assisted Image Analysis System in the Fusion of Landscape Architecture and Landscape Painting Theory [J]. Advanced Materials Research, 2013, 791-793:2018-2022.

[8] Yin Z Y. The application analysis on graphics image processing technology in statistics of soil crack [J]. Shanxi Architecture, 2012, 284(50):34880-8.

[9] Wang Y. Research on the Visual Communication Design Based on Technology of Computer Graphics [J]. Advanced Materials Research, 2014, 846-847:1064-1067.

[10] Den D S. The Application of Computer Graphics Technology in Resource Management [J]. Applied Mechanics \& Materials, 2014, 687-691:4914-4917.

[11] Zhou Y. Graphics and image processing technology in the apparel printing Application Test [J]. Laser Journal, 2014, 35(1):37-38.

[12] Wang Z Y. Graphic Image Processing Technology in the Application of the Film and Television Creation [J]. Advanced Materials Research, 2014, 1044-1045:1169-1172. 